Research Group: Food, Farms, and Firms

\title{
Are Fruit and Vegetable Stamp Policies Cost-Effective?
}

\author{
JEAN DALLONGEVILLE, LUC DAUCHET, \\ OLIVIER DE MOUZON, VINCENT RÉQUILLART
} AND LOUIS-GEORGES SOLER 


\title{
ARE FRUIT AND VEGETABLE STAMP POLICIES COST-EFFECTIVE?
}

\section{O. de Mouzon ${ }^{1}$, V. Réquillart ${ }^{1}$, L.G. Soler ${ }^{2}$, J. Dallongeville ${ }^{3}$ et L. Dauchet $^{3}$}

(1)Toulouse School of Economics (INRA, GREMAQ), F

(2) INRA-ALISS, Ivry-Seine, F

(3) Institut Pasteur de Lille, INSERM 744, F

\begin{abstract}
In many countries, consumption of fruits and vegetables $(\mathrm{F} \& \mathrm{~V})$ is below recommended levels. We quantify the economic and health effects of a F\&V stamp policy designed for lowincome consumers. The analysis combined two models: an economic model which predicts how F\&V consumption is affected by a change in policy and a health model which evaluates the impact of a change in F\&V consumption in terms of death avoided (DA) and life-years saved (LYS). We computed the costs per DA and LYS as the ratios between the taxpayer cost of the policy and the numbers of DA and LYS.

The main findings are: at the aggregate level, a F\&V stamp policy has a modest impact on consumption and as a result on health gains; however, when well designed, the F\&V stamp policy may increase the F\&V consumption of low-income households; to maximize the costeffectiveness of the F\&V stamp policy, the targeted population must be rather small; the F\&V stamp policy may be more cost-effective than a non-targeted policy based on a VAT decrease; a stamp policy may generate a small increase in the price of $F \& V$ thus reducing the consumption and the health benefits within the non targeted population.
\end{abstract}

KEY WORDS: Cost-Effectiveness Analysis, Fruits and Vegetables, Health Impact Assessment, Health Policy

JEL CODES: D61, I18, Q18. 


\section{Are Fruit and Vegetable Stamp Policies Cost-Effective?}

\section{Introduction}

Poor nutritional outcomes in disfavoured and low-income households are crucial issues for health policy makers in many industrialized countries (Lock et al., 2005). Population groups with high poverty rates and low education levels are indeed often reported to face higher obesity and overweight prevalence, associated with lower-quality diets, higher intakes of energy-dense foods and smaller consumption of fruits and vegetables (F\&V) (Blisard et al., 2004; Disball et al., 2007; Fox and Cole, 2004; Frazao, 2007; Wilde at al., 1999). Even if other factors seem to play important roles (French et al., 2001; Cassady et al. 2007), economic factors are frequently considered as major determinants of food behaviours, low incomes binding the food diet choices and limiting the ability to have adequate food intakes according to dietary guidelines (Bihan et al., 2010; Drewnowski at al., 2004; Drewnowski and Specter, 2004; Drewnowski and Darmon, 2005; Lin and Guthrie, 2007; Olson, 1999; Shenkin and Jacobson, 2010)).

In the United States, food assistance programs have been implemented for a long time to help disfavoured populations from an economic point of view (Landers, 2007). Beside education programs, Food Stamp Program (FSP) aims to increase food expenditures by delivering to the households monthly stamps only useable to buy foods. In present days, 25 millions of people are involved in this program and receive an average amount of 200 dollars per household per year. FSP is generally considered to be successful in the sense that it provided food assistance to many low-income people, leading to a decrease in child poverty and food insecurity (Le Blanc et al., 2007; Pan and Jensen, 2008; Wilde and Nord, 2005). However the impacts on diet quality and nutrient needs are more controversial and the goals related to the reduction of obesity and overweight prevalence are not always met (Chen et al., 2005; Jones and Frongillo, 
2006; Gibson, 2003 and 2006; Meyerhoefer and Pylypchuk, 2008; Ver Ploeg et al., 2007: Wilde et al., 2000; Webb et al., 2008). It is worthwhile to note that the FSP allows participants to buy any foods they want and thus to consume the same diet as previously, even if it is dominated by energy-dense foods and beverages (Fox et al., 2004; Fox and Cole, 2004; Frongillo, 2003). For this reason, some authors proposed to re-design the FSP to allow only the purchase of healthy foods, especially F\&V (Guthrie et al., 2007). Such a measure has been experimented within the Special Supplemental Nutrition Program for Women, Infants, and Children and the Food Stamp (WIC), in which pregnant women in low-income households get a $\$ 10$ voucher per week to purchase only fresh $F \& V$. This experiment confirmed that providing $F \& V$ vouchers would increase purchase and consumption of a wide variety of nutrient dense fresh F\&V among low income women and their families (Herman et al., 2008).

In Europe, food stamp programs have not been implemented yet, as food assistance programs rely mainly on charity associations which distribute food surpluses. However the increase in health inequalities and in obesity prevalence among low income populations led some policy makers to propose to implement $F \& V$ stamp programs ${ }^{1}$. Some local experiments have been made in France to assess the impacts of $€ 10$ monthly vouchers per person. First results seem to attest some positive effects on F\&V consumption (Bihan, 2008).

However, redesigning the FSP in the US by limiting their use to $F \& V$ purchases, or generalizing the first European experiments to every low income households raises the question of the cost-effectiveness of this policy. Cost-effectiveness of F\&V stamp policy depends on several factors. Firstly, it depends on the amount of money each participant gets to

\footnotetext{
${ }^{1}$ See for instance, the project discussed in the French Parliament in June 2010 (http://www.assembleenationale.fr/13/pdf/propositions/pion2671.pdf).
} 
buy F\&V. This amount depends on the total budget allocated to the policy and on the size of the targeted population. Secondly, it depends on the initial consumption patterns of each participant. It is well-known that the behaviour of the household will depend on the value of the stamp compared to the initial expenditure (Alston et al. 2009). If the stamp is smaller than the budget initially devoted to $\mathrm{F} \& \mathrm{~V}$ purchases, it acts as an increase in income and has the same effect on consumption as a cash transfer. If the stamp is greater, the value above the current F\&V expenditure is fully devoted to F\&V purchases. In the first case the impact is likely to be small while in the second it might be significant. Thirdly, the cost-effectiveness of the policy will depend on its aggregated effects on the participants and the non participants as well (Alston et al., 2009; Dallongeville et al., 2010). Indeed, if the program is successful it leads to an increase in the F\&V demand. Then, it is likely that all the households will face higher prices which can limit the consumption increase among the participants to the program and favour a consumption decrease among the non participants. Finally, the cost-effectiveness of such a policy will depend on the health benefits linked to an increase of F\&V consumption.

Following Cash et al. (2005) and Dallongeville et al. (2010), the goal of the paper is to assess the effects of the various dimensions mentioned above (budget allocated to the F\&V program, size of the targeted population, initial consumption and expenditures of the targeted population) on the economic and health impacts of a F\&V stamp policy. An economic model of the $\mathrm{F} \& \mathrm{~V}$ market is used to provide the impacts of the food stamp policy on $\mathrm{F} \& \mathrm{~V}$ consumption. Then a health model is used to assess the impact of the changes in $F \& V$ consumption levels on the number of deaths avoided (DA) and life-years saved (LYS) from non communicable diseases. This economic/health model is used to simulate a F\&V stamp policy and determine the modifications of $F \& V$ consumption among participants and non participants to the $\mathrm{F} \& \mathrm{~V}$ stamp program, depending on the budget allocated and the size of the 
targeted population. According to the health consequences assessed by simulation, we then compute the costs per DA and LYS induced by this policy. The simulations are made using French data.

Our results contribute to a larger debate in public health dealing with the compared benefits of targeted versus population-based prevention strategies. Introduced by Rose (1992), an argument in favour of non targeted strategies is that more disease can be often prevented by reducing a risk factor by a small amount in the total population than by selectively reducing it by a large amount in high-risks individuals. Considering risk factors such as cholesterol, Rose (2001) showed that a strategy that reduced the population average of cholesterol would lower the prevalence of clinical heart disease more than a strategy focused on people with the highest cholesterol values. This result has been discussed by several authors in relation to medical issues like risk prediction methods (Zulman et al., 2008) or to the costs of the interventions (Ahern et al., 2008). In this paper we continue this discussion by considering the potential effects of markets mechanisms on the trade-off between targeted / non targeted strategies. More precisely, we compare the targeted F\&V stamp policy to the impacts induced by a non targeted policy based on reduction of F\&V price thanks to a VAT decrease. Previous works showed that F\&V stamp policy seemed to be able to reduce health inequalities but its cost-effectiveness appeared to be smaller than non-targeted policies relying on F\&V price reduction or generic information campaigns (Dallongeville et al., 2010). We argue here that targeting the F\&V stamp policy is an important issue which can significantly affect its costeffectiveness. The health/economic model is used to determine to what extent, depending on the size of the targeted population, such a targeted F\&V stamp prevention strategy is better than a population-based strategy through a general $F \& V$ price decrease. 
We present the general economic model in section 1 , and the health model in section 2 . In section 3 we explain how these models are applied to simulate $\mathrm{F} \& \mathrm{~V}$ stamp policies and assess their cost-effectiveness. The main results are presented in section 4. The limits of our results and their policy implications are discussed in section 5.

\section{The economic model}

Equilibrium Displacement Models have been developed to analyze market impacts of various policies such as country of origin labeling (Lusk and Anderson, 2004), R\&D expenses (Wolghenant, 1993), or price floor mechanisms (Bouamra-Mechemache and Réquillart, 2000). In this paper we propose such a model in order to determine to what extent the current consumption of $\mathrm{F} \& \mathrm{~V}$ as the result of the market equilibrium between the F\&V supply and demand functions, could be modified by any change in policy variables, such as consumers' income or VAT rate.

In the following, we distinguish two segments in the population: the targeted population which benefits from the food-stamp policy and the non-targeted one. Within each population, we define $N j$ (with $j=1$ for the targeted population and $j=2$ for the non-targeted population) groups of consumers according to their consumption of F\&V. Without loss of generality, in population 1, groups are ordered according to an increasing level of consumption. Formally, the market equilibrium is defined by the following equations:

$$
\begin{aligned}
& Q_{d 1}=\sum_{j=1}^{N_{1}} q_{1}^{j}=\sum_{j=1}^{N_{1}} g_{1}^{j}\left(P_{d}, Y_{1}\right) \\
& Q_{d 2}=\sum_{j=1}^{N_{2}} q_{2}^{j}=\sum_{j=1}^{N_{2}} g_{2}^{j}\left(P_{d}, Y_{2}\right) \\
& Q_{d}=Q_{d 1}+Q_{d 2}
\end{aligned}
$$


$Q_{s}=f\left(P_{s}\right)$

$Q_{s}=Q_{d}$

$P_{d}=(1+\tau) P_{S}$

with $Q_{d}$ the total quantity demanded, $q_{1}^{j}$ and $q_{2}^{j}$ the quantities demanded by group $j$ of consumers in populations 1 and 2 respectively, $N_{1}$ and $N_{2}$ the number of groups of consumers in populations 1 and 2, $Q_{d 1}$ and $Q_{d 2}$ the quantities demanded by populations 1 and 2, $P_{d}$ the consumer price, $Y_{1}$ and $Y_{2}$ the income of populations 1 and 2, $Q_{s}$ the quantity supplied, $P_{S}$ the producer price, and $\tau$ the tax coefficient. In this setting, prices and quantities are the endogenous variables while the other ones (income, tax coefficient) are exogenous.

Equations (1) and (2) define the demand function for the two populations. It is the sum of demand functions from each group of consumers. These demands depend on consumer price and income. Obviously demand depends on other elements (such as information for example) which are integrated here in the $g$ function which is a characteristic of the group. We assume that the good consumed is homogenous; then both populations are facing the same consumer price. Moreover, we consider that the income is population specific but not group specific. Equation (3) states that the total quantity demanded is the sum of the demand from populations 1 and 2. Equation (4) states that the supply depends on producer price. ${ }^{2}$ Equation (5) states that at equilibrium the quantity demanded is equal to the quantity supplied. Finally equation (6) defines the relation between the consumer price and the producer price.

\footnotetext{
${ }^{2}$ Obviously supply depends on other elements but they will play no role here as they are considered to be exogenous and not affected by the policy variables. We can thus neglect them.
} 
Totally differentiating the set of equations (1) to (6) leads to the following system which relates the relative change of endogenous variables to the relative change of exogenous variables:

$$
\left[\begin{array}{cccccc}
1 & 0 & 0 & 0 & 0 & -\varepsilon_{\mathrm{p}}^{1} \\
0 & 1 & 0 & 0 & 0 & -\varepsilon_{\mathrm{p}}^{2} \\
-\alpha & \alpha-1 & 1 & 0 & 0 & 0 \\
0 & 0 & 0 & 1 & -\eta_{\mathrm{p}}^{\mathrm{s}} & 0 \\
0 & 0 & 1 & -1 & 0 & 0 \\
0 & 0 & 0 & 0 & -1 & 1
\end{array}\right]\left[\begin{array}{l}
\mathrm{EQ}_{\mathrm{d} 1} \\
\mathrm{EQ}_{\mathrm{d} 2} \\
\mathrm{EQ}_{\mathrm{d}} \\
\mathrm{EQ_{ \textrm {s } }} \\
\mathrm{EP_{ \textrm {s } }} \\
\mathrm{EP_{ \textrm {d } }}
\end{array}\right]=\left[\begin{array}{c}
\varepsilon_{\mathrm{Y}}^{1} \mathrm{EY}_{1} \\
\varepsilon_{\mathrm{Y}}^{2} \mathrm{EY}_{2} \\
0 \\
0 \\
0 \\
\tau \mathrm{E} /(1+\tau) \tau
\end{array}\right]
$$

denoting EX the ratio $\mathrm{dX} / \mathrm{X}$ with $\mathrm{X}$ representing any variable; and with $\eta_{p}^{S}=\frac{\partial f}{\partial P_{s}} \frac{P_{s}}{Q_{s}}$ the ownprice elasticity of supply, $\varepsilon_{p}^{i}=\sum_{j=1}^{N_{j}} \alpha_{i}^{j} \frac{\partial g_{i}^{j}}{\partial P_{d}} \frac{P_{d}}{q_{i}^{j}}=\sum_{j=1}^{N_{j}} \alpha_{i}^{j} \varepsilon_{p}^{i, j}$ the own-price elasticity of demand of population $i\left(\alpha_{i}^{j}\right.$ and $\varepsilon_{p}^{i, j}$ are the share of consumption and the own-price elasticity of demand of group $j$ in population $i$, respectively), $\varepsilon_{Y}^{i}=\sum_{j=1}^{N_{j}} \alpha_{i}^{j} \frac{\partial g_{i}^{j}}{\partial Y_{i}} \frac{Y_{i}}{q_{i}^{j}}=\sum_{j=1}^{N_{j}} \alpha_{i}^{j} \varepsilon_{Y}^{i, j}$ the income elasticity of demand of population $i\left(\varepsilon_{Y}^{i, j}\right.$ is the income elasticity of demand of group $j$ in population $i$ ), and $\alpha=\frac{Q_{\mathrm{d} 1}}{Q_{\mathrm{d} 1}+\mathrm{Q}_{\mathrm{d} 2}}$ the share of demand from population 1 . The own-price and income elasticities of demand of population $i$ are a weighted average of the respective elasticities over the groups in population $i$. In the standard case, we have $\eta_{\mathrm{p}}^{\mathrm{s}}>0 ; \varepsilon_{\mathrm{p}}^{1}<0 ; \varepsilon_{\mathrm{p}}^{2}<0 ; \varepsilon_{\mathrm{Y}}^{1}>0 ; \varepsilon_{\mathrm{Y}}^{2}>0$.

To analyze the impact of a change in exogenous variables on endogenous variables, the system of equations (7) is solved given the value of the change in exogenous variables. For example, a relative increase in income by $E Y_{1}$ leads to an exogenous shift of demand (in \%) from population 1 by $\varepsilon_{Y}^{1} E Y_{1}$. Then this exogenous shift in demand generates a change in consumption taking into account price adjustments that are evaluated by solving the model. 


\subsection{Impact of a change in the tax rate}

By decreasing the tax rate the public authority favors F\&V consumption. To infer the impact of this policy, we solved the system (7) with $E \tau \neq 0$, while the other exogenous variables are kept constant $\left(E Y_{i}=0\right)$. We get:

$E Q_{d 1}=\frac{\varepsilon_{p}^{1} \eta_{p}^{s}}{A_{2}} E \tau ; E Q_{d 2}=\frac{\varepsilon_{p}^{2} \eta_{p}^{s}}{A_{2}} E \tau$

$E Q_{d}=E Q_{s}=\frac{\left[\alpha \varepsilon_{p}^{1}+(1-\alpha) \varepsilon_{p}^{2}\right] \eta_{p}^{s}}{A_{2}} E \tau$

$E P_{d}=\frac{\eta_{p}^{S}}{A_{2}} E \tau$

$E P_{S}=\frac{\left[\alpha \varepsilon_{p}^{1}+(1-\alpha) \varepsilon_{p}^{2}\right]}{A_{2}} E \tau$

with $A_{2}=\eta_{p}^{S}-\alpha \varepsilon_{p}^{d 1}-(1-\alpha) \varepsilon_{p}^{d 2}>0$ in the standard case. Then, a decrease in the rate of taxation $(E \tau<0)$ leads to a higher consumption, to a lower consumer price and to a higher producer price. It is easy to show that for a given decrease in the rate of taxation, the increase in consumption is higher when the demand is more elastic or the supply is more elastic.

\subsection{Impact of a F\&V stamp policy}

F\&V stamp policy must be analyzed by considering that $\mathrm{F} \& \mathrm{~V}$ stamps act through two channels. Assume first that the value of the F\&V stamp (denoted $S$ ) given to a consumer $j$ is lower than her current expenditure in $\mathrm{F} \& \mathrm{~V}$ (denoted $F V_{1}^{j}$ ). In this case, the $\mathrm{F} \& \mathrm{~V}$ stamp is equivalent to a change in income: this is the first channel. To get the intuition, assume that $S \leq F V_{1}^{j}$ and that the consumer does not change her habits. This consumer uses the $F \& V$ stamp to purchase part of her consumption of $F \& V$. By doing so, the consumer saves money which can be used for any other use. Then, the F\&V stamp is equivalent to a change in income (see Alston et al. (2009) for a discussion). However, if the value of the F\&V stamp is larger to the current expenditure, there is a second channel. The consumer is somewhat forced to buy a larger quantity of $\mathrm{F} \& \mathrm{~V}$. The corresponding relative increase in consumption is equal 
to $\left(S-F V_{1}^{j}\right) / P_{d} q_{1}^{j}$. Thus when the value of the $\mathrm{F} \& \mathrm{~V}$ is larger than current expenditure, the impact comes from the two channels: the 'income' channel for a value equal to the current expenditure and the second one for the remaining part. In term of modeling, first row of (7) only takes into account the first channel, implicitly assuming 'small' value F\&V stamps. To generalize to any value of F\&V stamp, we need to take into account the second channel.

To formalize this, let first define $\widetilde{N}_{1}$ such that:

$\forall j=1, \ldots, \widetilde{N}_{1} F V_{1}^{j} \leq S$ and $\forall j=\widetilde{N}_{1}+1, \ldots, N_{1} F V_{1}^{j}>S .^{3}$

Depending on the group, the $\mathrm{F} \& \mathrm{~V}$ stamp acts through both channels or through only the income channel. The exogenous change of demand (in \%) due to the F\&V stamp policy is given by:

$E q_{1}^{j}=\varepsilon_{Y}^{1, j} F V_{1}^{j} / Y_{1}+\left(S-F V_{1}^{j}\right) / P_{d} q_{1}^{j} \forall j=1, \ldots, \widetilde{N}_{1}$

$E q_{1}^{j}=\varepsilon_{Y}^{1, j} S / Y_{1} \forall j=\widetilde{N}_{1}+1, \ldots, N_{1}$,

with $E q_{1}^{j}$ representing the (exogenous) percentage variation of demand from consumer $j$. Then, summing for all groups of consumers, the first row of (7) is now written as:

$$
\begin{aligned}
& \mathrm{EQ}_{\mathrm{d} 1}=\quad \varepsilon_{\mathrm{p}}^{1} \mathrm{EP}_{\mathrm{d}}+\sum_{\mathrm{j}=1}^{\mathrm{N}_{1}} \alpha_{1}^{j} E q_{1}^{j} \\
& =\varepsilon_{\mathrm{p}}^{1} \mathrm{EP}_{\mathrm{d}}+\sum_{\mathrm{j}=1}^{\widetilde{\mathrm{N}}_{1}} \alpha_{1}^{j}\left(\varepsilon_{Y}^{1, j} F V_{1}^{j} / Y_{1}+\left(S-F V_{1}^{j}\right) / P_{d} q_{1}^{j}\right)+\sum_{\mathrm{j}=\widetilde{\mathrm{N}}_{1}+1}^{\mathrm{N}_{1}} \alpha_{1}^{j}\left(\varepsilon_{Y}^{1, j} \mathrm{~S} / Y_{1}\right) \\
& \mathrm{EQ}_{\mathrm{d} 1}-\varepsilon_{\mathrm{p}}^{1} \mathrm{EP}_{\mathrm{d}}=\sum_{\mathrm{j}=1}^{\mathrm{N}_{1}} \alpha_{1}^{j}\left(\varepsilon_{Y}^{1, j} \operatorname{Min}\left[F V_{1}^{j}, S\right] / Y_{1}\right)+\sum_{\mathrm{j}=1}^{\mathrm{N}_{1}} \alpha_{1}^{j}\left(\operatorname{Max}\left[0,\left(S-F V_{1}^{j}\right)\right] / P_{d} q_{1}^{j}\right)
\end{aligned}
$$


The right hand side of (12) is the sum of two terms. The first one corresponds to the exogenous change in demand due to the income effect (channel 1) and the second one to the exogenous change in demand due to the 'forced' increase in consumption. Both terms are a weighted sum of the impact on each group. These two terms thus represents the exogenous change in demand due to the $F \& V$ stamps given to population 1 . We denote $E D_{1}$ the sum of these two terms, writing (12) as $\mathrm{EQ}_{\mathrm{d} 1}-\varepsilon_{\mathrm{p}}^{1} \mathrm{EP}_{\mathrm{d}}=\mathrm{ED}_{1}$ which is the new form of the first row in (7) with $\mathrm{ED}_{1}=\sum_{\mathrm{j}=1}^{\mathrm{N}_{1}} \alpha_{1}^{j}\left(\varepsilon_{Y}^{1, j} \operatorname{Min}\left[F V_{1}^{j}, S\right] / Y_{1}\right)+\sum_{\mathrm{j}=1}^{\mathrm{N}_{1}} \alpha_{1}^{j}\left(\operatorname{Max}\left[0,\left(S-F V_{1}^{j}\right)\right] / P_{d} q_{1}^{j}\right)$.

The system (7) is now solved with $E \tau=0, E Y_{2}=0$ and $E D_{1}>0$, we get:

$$
\begin{aligned}
& E Q_{d 1}=\left(1+\frac{\alpha \varepsilon_{p}^{d 1}}{A_{2}}\right) E D_{1} \\
& E Q_{d 2}=\left(\frac{\alpha \varepsilon_{p}^{d 2}}{A_{2}}\right) E D_{1} \\
& E Q_{d}=E Q_{S}=\left(\frac{\alpha \eta_{p}^{s}}{A_{2}}\right) E D_{1} \\
& E P_{d}=E P_{S}=\left(\frac{\alpha}{A_{2}}\right) E D_{1}
\end{aligned}
$$

Note that (13) to (16) are an approximation of the real effect as by writing (13) to (16) we neglect the changes of the consumer price in the value of $\mathrm{ED}_{1}{ }^{4}$ Equation (13) provides the relative change of consumption in population 1 . It is the sum of the relative increase in consumption at constant price $\left(E D_{1}\right)$ and the relative decrease in consumption $\left(\frac{\alpha \varepsilon_{p}^{d 1}}{A_{2}} E D_{1}\right)$ due to the price increase (Equation (16)). The final relative increase of consumption by population 1 is positive as the indirect and negative price effect is lower than the direct and positive

\footnotetext{
${ }^{4}$ The computed price effect is small (lower than $1 \%$ in any case) thus justifying this approximation and the way we deal with.
} 
effect of $\mathrm{F} \& \mathrm{~V}$ stamps. The quantity consumed by population 2 always decreases $\left(E Q_{d 2}<0\right)$ as population 2 only faces the price increase.

\section{The health model}

Owing to the well-documented association between F\&V consumption and cancer or cardiovascular diseases, we focused the analysis only on these major causes of death. Table 1 gives the relative risks (RRs) of specific causes of death associated with an increase by one serving of $\mathrm{F} \& \mathrm{~V}$, i.e. the decrease in the probability of each disease induced by an additional consumption of $80 \mathrm{~g} / \mathrm{day}$. These data were taken from recently published meta-analyses for cancer deaths and for cardiovascular deaths (coronary and stroke) (Dauchet et al., 2005; Dauchet et al., 2006). To assess the number of deaths by cancer and cardiovascular disease avoided by changes in F\&V intake, we hypothesized a log linear dose effect relationship using the following formula: $\left(1-R R^{\Delta F \& V}\right) *$ number of deaths, where $R R$ is the relative risk for an additional serving per day and $\triangle F \& V$ is the change in $F \& V$ intake (in servings of $80 \mathrm{~g}$ per day). The number of LYS was estimated by multiplying the number of DA by the mean expected number of years of life lost for each disease. To evaluate the latter, we used recent mortality and cause specific mortality data for France in 2006 (additional details in Dallongeville et al., 2010). We estimated the life expectancy at each age using French mortality data on total deaths. Then an expected number of years of life lost for each cause of death was calculated according to distributions of causes of death by age (Murray, 1994).

To account for the effect of social disparities on disease rates we used the relative inequality index (RII) associated with occupational status in France (Saurel-Cubizolles et al., 2009), thus estimating cancer and cardiovascular death rates in the lowest deciles of income distribution of the French population. Owing to the lack of specific RII values for each cancer type and for 
stroke or coronary heart diseases, we used the following values: 4.53 [3.94-5.21] and 2.09 [1.71-2.56] for cancers and 4.50 [3.65-5.54] and 5.84 [3.94-8.65] for cardiovascular diseases, in men and women respectively. Numbers in brackets represent 95\% confidence intervals.

\begin{tabular}{|c|c|c|c|c|c|}
\hline \multirow{2}{*}{ Disease } & \multirow{2}{*}{$\begin{array}{l}\text { RR for one aditional } \\
\text { serving of fruits and } \\
\text { vegetables: } \\
\text { Mean [CI 95\%] }\end{array}$} & \multicolumn{2}{|c|}{ Number of deaths } & \multicolumn{2}{|c|}{$\begin{array}{c}\text { Expected number of } \\
\text { years of life lost per death }\end{array}$} \\
\hline & & $\begin{array}{c}\text { Whole } \\
\text { population }\end{array}$ & $\begin{array}{c}\text { First decile } \\
\text { of income }\end{array}$ & Men & Women \\
\hline \multicolumn{6}{|l|}{ Cancer } \\
\hline Mouth, pharynx and larynx & $0.92[0.81-1.06]$ & 5,536 & 1,013 & 18.5 & 20.4 \\
\hline Esophagus & $0.92[0.85-1.00]$ & 3,837 & 696 & 16.1 & 15.8 \\
\hline Stomach & $0.97[0.93-1.01]$ & 4,763 & 820 & 13.7 & 13.7 \\
\hline Pancreas & $0.97[0.90-1.04]$ & 8,263 & 1,369 & 14.5 & 13.9 \\
\hline Lung & $0.94[0.92-0.97]$ & 28,347 & 5,088 & 16.0 & 20.0 \\
\hline Colon and rectum & 0.99 [0.94 - 1.04] & 16,426 & 2,733 & 12.4 & 12.6 \\
\hline Ovary & $0.84[0.62-1.13]$ & 3,342 & 463 & & 17.1 \\
\hline \multicolumn{6}{|l|}{ Cardiovascular disease } \\
\hline Coronary heart disease & 0.97 [0.94 - 0.99] & 38,806 & 7,497 & 11.6 & 8.4 \\
\hline Stroke & $0.96[0.94-0.98]$ & 32,652 & 6,335 & 10.2 & 8.8 \\
\hline
\end{tabular}

Table 1. Estimated relative risks (RR) of death for one additional portion of $F \& V$, number of deaths and expected number of years of life lost per each cause of death.

Table 1 clearly shows that, in proportion of the population, the number of deaths related to cancer and cardiovascular diseases among poor people (here the first decile of income) are much higher than in the population considered as a whole.

\section{Empirical simulations}


Using data from the INCA 2 survey (http://www.afssa.fr/index.htm) which provides (among others) the $\mathrm{F} \& \mathrm{~V}$ consumption as well as income, we distinguished low income consumers (LIC) who belong to the first decile of income from standard income consumers (SIC). The first decile of income is approximately composed of people who live under the poverty threshold. Those two segments of consumers differ by the distribution of F\&V consumption with LIC consuming less than SIC (see Table 2).

\begin{tabular}{|l|c|c|}
\hline Daily Consumption & \multicolumn{2}{|c|}{ Proportion of consumers (\%) } \\
\hline & $\begin{array}{c}\text { Low Income } \\
\text { Consumers (LIC) }\end{array}$ & $\begin{array}{c}\text { Standard Income } \\
\text { Consumers (SIC) }\end{array}$ \\
\hline$<100$ g/day & 18 & 8 \\
\hline$<200$ g/day & 38 & 24 \\
\hline$<300$ g/day & 55 & 41 \\
\hline$<400$ g/day & 68 & 72 \\
\hline$<500$ g/day & 82 & 83 \\
\hline$<600$ g/day & 90 & 390 \\
\hline & Consumption (g/day) \\
\hline Mean & 315 & 355 \\
\hline Median & 262 & 72 \\
\hline
\end{tabular}

Table 2: Distribution of F\&L consumption in the two sub-populations

We evaluate the $\mathrm{F} \& \mathrm{~V}$ stamp policy for different rates of targeting, the targeted population (that is population 1 in the theoretical model) being a part of LIC if the rate of targeting is lower than $10 \%$, or all the LIC if the rate of targeting is $10 \%$. This means that in the empirical model, population 2 is the combination of non-targeted LIC (if any) and SIC (who are always non-targeted). Then, targeted consumers are characterized by the distribution of consumption 
of LIC while non targeted consumers have a distribution of consumption which is the aggregation of distribution of consumption from non targeted LIC and from SIC.

We use average value of income for each population. That is LIC has an average income of $7472 € /$ year (INSEE $2006^{5}$ ) and SIC $21885 € /$ year. When targeting only a part of LIC, we also use the average income of the targeted population according to INSEE data.

The extent of the consumers' or producers' responses to any policy depends on the value of the economic parameters of the model especially the price, income and supply elasticities. Price and income elasticities of demand were mainly defined on the basis of the French studies mentioned in Table 3. It appears that the price elasticity of demand of the whole population for different categories of $F \& V$ ranges between -0.24 and -1.15 . Price elasticity of demand from low income population ranges between a low price elasticity of -0.06 to a high elasticity of -1.27 . These results do not provide strong evidence of a significant difference of behavior between LIC and SIC. Then we calculated the average and standard deviation from these studies (-0.85 and 0.3 respectively) and used these values to characterized the price elasticity of demand of both populations.

With respect to supply elasticity, we did not find any study referring specifically to France. However, contrary to the F\&V demand which is likely to be country-specific, the producers' flexibility of supply is more similar from one country to another. For this reason, we considered that it was admissible to use values obtained in non French studies. For instance, Alston et al. (2009) in a study on food stamps in the US, use a supply elasticity of 1.0 arguing that it reflects medium run response. Jetter et al. (2004) analyze the impact of '5 a day' campaign and consider the following values for the supply price elasticity of vegetables, fruits

\footnotetext{
${ }^{5}$ http://www.insee.fr/fr/themes/tableau.asp?reg_id=0\&ref_id=NATnon04249.
} 
and perennial crops: 0.5, 1.0 and 0.75 (respectively) for low values and 1.0, 1.5 and 1.25 (respectively) for high values. In this study, we thus chose a value of 1 for the price elasticity of supply with a standard deviation of 0.25 .

\begin{tabular}{|c|c|c|c|c|}
\hline & & Price elasticity & Price elasticity & Income Elasticity \\
\hline & & $\begin{array}{c}\text { Whole } \\
\text { population }\end{array}$ & $\begin{array}{c}\text { Poor } \\
\text { households }\end{array}$ & $\begin{array}{c}\text { Poor } \\
\text { Households }\end{array}$ \\
\hline \multirow{2}{*}{ Nichele' (2003) } & Fruits & $-0,7$ & & \\
\hline & Vegetables & $-0,92$ & & \\
\hline \multirow{2}{*}{$\begin{array}{c}\text { Andrieu and } \\
\text { Caillavet (2006) }\end{array}$} & Fruits & & & 0,89 \\
\hline & Vegetables & & & 0,3 \\
\hline \multirow{4}{*}{$\begin{array}{l}\text { Andrieu et al.ii } \\
\qquad(2006)\end{array}$} & Fresh Fruits & $-1,06$ & $-0,89$ & 0,22 \\
\hline & $\begin{array}{c}\text { Fresh } \\
\text { Vegetables }\end{array}$ & $-1,06$ & $-0,82$ & 0,22 \\
\hline & $\begin{array}{l}\text { Processed } \\
\text { Fruits }\end{array}$ & $-0,79$ & $-1,15$ & 0,37 \\
\hline & $\begin{array}{l}\text { Processed } \\
\text { Vegetables }\end{array}$ & $-1,02$ & $-1,03$ & 0,27 \\
\hline \multirow{3}{*}{$\begin{array}{l}\text { Allais et al. } \text { Iv }^{\text {(2008) }}\end{array}$} & Fresh Fruits & $-0,24^{*}$ & $-0,06$ & \\
\hline & $\begin{array}{c}\text { Fresh } \\
\text { Vegetables }\end{array}$ & $-0,34^{*}$ & $-0,2$ & \\
\hline & $\begin{array}{l}\text { Processed } \\
\text { Fruits }\end{array}$ & $-0,58^{*}$ & $-0,61$ & \\
\hline
\end{tabular}

(* elasticities for non poor people rather than for the whole population)

Table 3: Price and income elasticities in France

The parameters of the model (3 economic and 13 health parameters) were supposed to follow independent lognormal distributions. Monte-Carlo simulations were performed by drawing 10 million times a 16-uplet of parameters. For each uplet, we computed the changes induced by each policy scenario for the following variables: F\&V consumption for each category of 
consumers, number of statistical DA, number of statistical LYS, cost per statistical DA, cost per statistical LYS. We then calculate the median and the 2.5 and 97.5 centiles for each variable. Finally we determine whether the policies reduce or not the health disparities within the population computing an odds-ratio defined as:

$\frac{[\% \text { death among LIC population / (1-\% death among LIC population)] }}{\text { [\% death among SIC population / (1-\% death among SIC population)] }}$

To facilitate the comparison between price policy and F\&V stamp policy, we ran simulations for a given ex ante budget allocated to the policy. We choose $300 \mathrm{M} €$. Targeting $5 \%$ of the population with this budget allows for a monthly $€ 10$ stamp. This amount is the same than the stamp amount given to poor individuals in the experiment implemented in France (Bihan, 2008). The VAT reduction allowed with such a budget is $3.06 \%$, which is close to the maximum potential reduction of VAT (current VAT is $5.5 \%$ and the lowest rate is $2.1 \%$, that is $3.4 \%$ reduction).

\section{Results}

Impact of the price policy

The decrease in VAT generates a decrease in consumer price by $1.2 \%$ which in turn leads to an average increase in consumption of $3.7 \mathrm{~g} /$ day. The increase in consumption by SIC consumers is slightly larger than the one of LIC consumers as they have a higher initial consumption. The median number of DA and LYS for the whole population is 279 and 3851 respectively. The mean cost per LYS is $78 \mathrm{k} €[45-146] .{ }^{6}$

\footnotetext{
${ }^{6} 2.5$ and 97.5 centiles are given in brackets.
} 
Impact of the F\&V stamp policy

For a given amount of financing, the impact of F\&V stamp policy decreases with the rate of targeting. ${ }^{7}$ Thus, for a $300 \mathrm{M} €$ budget, the median increase in consumption for the whole population is $0.4 \mathrm{~g} /$ day when targeting is $10 \%, 0.8 \mathrm{~g} /$ day when it is $5 \%, 1.9 \mathrm{~g} /$ day when it is 2\% (Table 4). Targeted population increases significantly her consumption while non-targeted population (whatever they are LIC or SIC) decreases her consumption due to the price effect. For example, when targeting $2 \%$ of the population the median increase in consumption for targeted consumers is 168.6 g/day while the median consumption for non-targeted LIC and SIC consumers decreases by 1.3 and 1.6 g/day, respectively. In this example, the increase in demand from targeted consumers generates a slight increase in the consumer price $(0.5 \%)$ leading to a decrease in the consumption of non-targeted consumers. The change in consumption of targeted consumers crucially depends on the rate of targeting. For example, it is $6.2 \mathrm{~g}$ /day when targeting $10 \%$ of the population, $27.0 \mathrm{~g}$ /day when targeting $5 \%$ and 168.6 g/day when targeting $2 \%$ of the population respectively.

\footnotetext{
${ }^{7}$ Note that a higher rate of targeting means that the targeted population is larger.
} 


\begin{tabular}{|c|c|c|c|c|c|c|c|c|c|c|c|c|}
\hline \multirow{2}{*}{ Policy comparison } & \multicolumn{3}{|c|}{ VAT reduction by 3.06 points } & \multicolumn{3}{|c|}{ Targeted LIC $=10 \%$} & \multicolumn{3}{|c|}{ Targeted LIC $=5 \%$} & \multicolumn{3}{|c|}{ Targeted LIC $=2 \%$} \\
\hline & Median & $2.5 \%{ }^{\text {ile }}$ & $97.5 \%$ ile & Median & $2.5 \%$ ile & $97.5 \%$ ile & Median & $2.5 \%$ ile & $97.5 \%$ ile & Median & $2.5 \%^{\text {ile }}$ & $97.5 \%{ }^{\text {ile }}$ \\
\hline \multicolumn{4}{|c|}{ Value of the $F \& V$ stamp ( $€ /$ year for each targeted person) } & \multicolumn{2}{|l|}{63} & \multicolumn{3}{|c|}{126} & \multicolumn{4}{|c|}{314} \\
\hline Consumer price variation (\%) & -1.23 & -1.65 & -0.78 & 0.09 & 0.06 & 0.15 & 0.20 & 0.13 & 0.31 & 0.49 & 0.33 & 0.74 \\
\hline \multicolumn{13}{|l|}{ Individual consumption variation (g/day) } \\
\hline Targeted LIC & 3.1 & 2.0 & 4.7 & 6.2 & 5.6 & 8.4 & 27.0 & 25.6 & 32.4 & 168.6 & 164.8 & 182.8 \\
\hline Non-targted LIC & 3.1 & 2.0 & 4.7 & & & & -0.5 & -0.8 & -0.3 & -1.3 & -1.9 & -0.8 \\
\hline Non-targeted SIC & 3.8 & 2.4 & 5.7 & -0.3 & -0.5 & -0.2 & -0.6 & -1.0 & -0.4 & -1.6 & -2.3 & -0.9 \\
\hline Whole population & 3.7 & 2.4 & 5.6 & 0.4 & 0.2 & 0.5 & 0.8 & 0.5 & 1.1 & 1.9 & 1.2 & 2.5 \\
\hline \multicolumn{13}{|l|}{ Number of death avoided (DA) } \\
\hline Targeted LIC & 9 & 5 & 16 & 89 & 57 & 133 & 202 & 133 & 281 & 486 & 321 & 650 \\
\hline Non-targted LIC & 34 & 19 & 57 & & & & -3 & -6 & -2 & -14 & -23 & -7 \\
\hline Non-targeted SIC & 235 & 128 & 401 & -19 & -33 & -9 & -40 & -68 & -20 & -98 & -164 & -50 \\
\hline Whole population & 279 & 152 & 474 & 70 & 44 & 106 & 157 & 101 & 225 & 370 & 240 & 512 \\
\hline Cancer & 165 & 75 & 301 & 38 & 19 & 62 & 84 & 44 & 130 & 190 & 97 & 285 \\
\hline Cardio-Vascular & 112 & 52 & 204 & 32 & 16 & 53 & 73 & 37 & 116 & 180 & 93 & 276 \\
\hline \multicolumn{13}{|l|}{ Number of of life-years saved (LYS) } \\
\hline Targeted LIC & 126 & 69 & 214 & 1198 & 759 & 1796 & 2718 & 1752 & 3794 & 6470 & 4216 & 8636 \\
\hline Non-targted LIC & 456 & 249 & 777 & & & & -47 & -80 & -24 & -190 & -317 & -98 \\
\hline Non-targeted SIC & 3268 & 1741 & 5619 & -260 & -463 & -129 & -555 & -952 & -278 & -1359 & -2296 & -685 \\
\hline Whole population & 3851 & 2062 & 6607 & 930 & 581 & 1426 & 2093 & 1332 & 3003 & 4855 & 3115 & 6708 \\
\hline Cancer & 2738 & 1269 & 4968 & 620 & 326 & 1011 & 1381 & 736 & 2127 & 3109 & 1639 & 4610 \\
\hline Cardio-Vascular & 1099 & 501 & 2006 & 310 & 154 & 515 & 711 & 356 & 1124 & 1748 & 888 & 2677 \\
\hline Mean cost per DA (M€) & 1.08 & 0.63 & 1.97 & 4.31 & 2.82 & 6.81 & 1.91 & 1.33 & 2.96 & 0.81 & 0.59 & 1.25 \\
\hline Mean cost per LYS (k€) & 78 & 45 & 146 & 323 & 210 & 517 & 143 & 100 & 225 & 62 & 45 & 96 \\
\hline $\begin{array}{c}\text { Health disparity index: } \\
\text { odds-ratio (LIC vs. SIC) variation }\end{array}$ & 0.001 & 0.000 & 0.002 & -0.007 & -0.011 & -0.005 & -0.016 & -0.023 & -0.011 & -0.039 & -0.052 & -0.026 \\
\hline
\end{tabular}

Table 4. Policy comparison: simulation Results (Total budget=300 M€) for LIC and SIC (Low and Standard Income Consumers) 
Figure 1 provides the initial and final distribution of F\&V consumption of LIC distinguishing between targeted consumers and non targeted consumers. ${ }^{8}$ Among the targeted population, the increase in consumption mainly concerns those who have a 'small' initial level of consumption, that is consumers for which the value of the food stamp was higher than their initial consumption of F\&V. All those consumers, when implementing the policy, consume (almost) the same quantity which is the value of the stamp divided by the price of F\&V. ${ }^{9}$

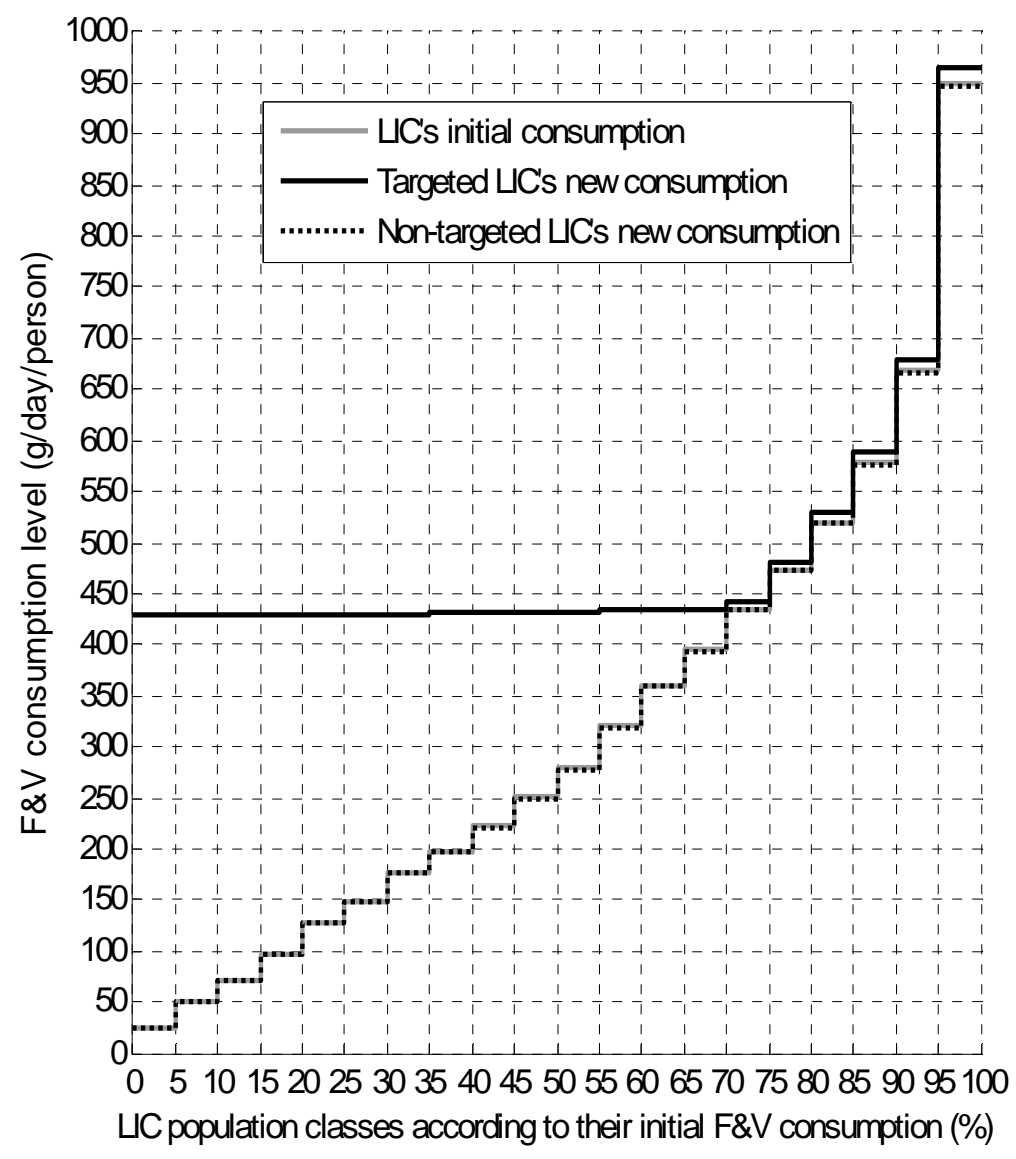

Figure 1. Initial and Final F\&V consumption of LIC (Low Income Consumers) when F\&V stamps are provided to $2 \%$ of the population (Total budget=300 M€)

\footnotetext{
${ }^{8}$ Results for non-targeted SIC are similar to the one presented for non-targeted LIC. That is basically a slight decrease in consumption.

${ }^{9}$ It is slightly increasing with the initial consumption, as a part of the F\&V stamp equal to the initial expenditure of each consumer acts as an increase in income which is partly used for purchasing F\&V. As initial expenditure depends on consumer, we get a slightly increasing curve.
} 
Consumers with an initial level of expenditure larger than the value of the F\&V stamp slightly increase their consumption. Non targeted consumers decrease only slightly their consumption as they face a price increase. The larger the initial consumption is, the larger the magnitude of this effect.

In line with the change in consumption, the numbers of DA and LYS increase when the rate of targeting decreases (Table 4). When targeting $10 \%$ of the population, the median numbers of DA and LYS are respectively 70 [44-106] and 930 [581-1426], while targeting $2 \%$ of the population leads to median numbers of DA and LYS which are respectively 370 [240-512] and 4855 [3115-6708]. As a consequence the health disparities between SIC and LIC populations decrease when the size of the targeted population decreases: the health benefits obtained by the targeted LIC population are greater than the price related deleterious health effects on the non targeted LIC and SIC population (see the odds-ratio variation in Table 4).

Similarly, the cost per statistical LYS decreases when the rate of targeting decreases. It is $323 \mathrm{k} €$ [210 - 517] when targeting 10\% of the population, $143 \mathrm{k} €$ [100 - 225] when targeting $5 \%$, and $62 \mathrm{k} €[45$ - 96] when targeting $2 \%$.

Thus, targeting a lower fringe of the population decreases the cost per LYS (or DA) of the policy. However, there is a limit. When targeting on fewer people (lower than $1 \%$ of the population in our example), the cost per LYS strongly increases (Figure 2a). This is because the number of LYS in the targeted population is now small due to the size of the population. The negative impact in the non targeted population might be larger than the positive impact in the targeted population. With a $300 \mathrm{M} €$ budget devoted to the policy, the optimal targeting is about $1 \%$ of the population that is roughly 500000 adults in France. 


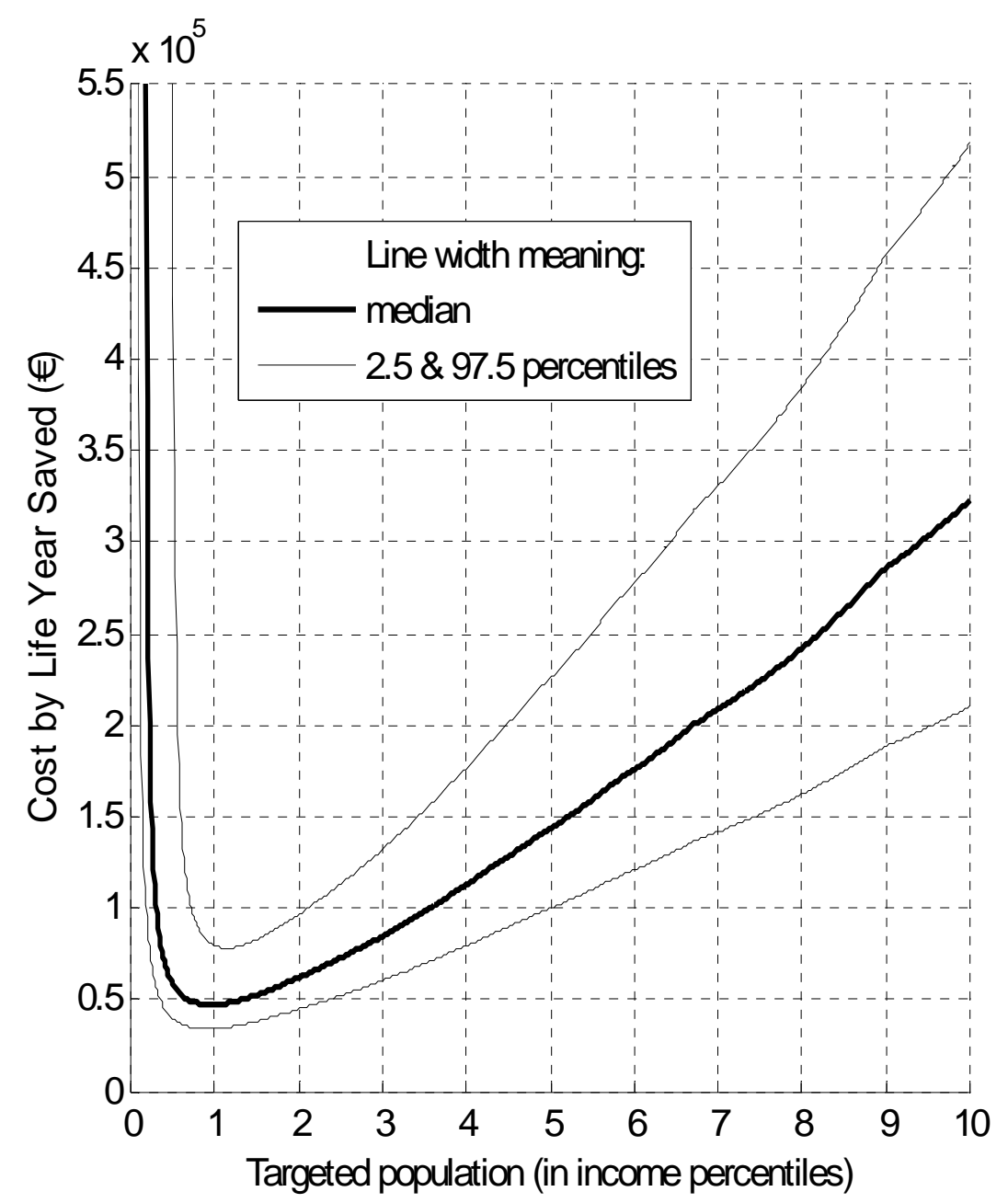

Figure 2a. Cost by LYS according to the size of targeted population (Total budget $=300 \mathrm{M} €$ )

When targeting is large (Figure 2b), the cost per LYS is high but varies at a lower rate with targeting. In this zone, the value of the $\mathrm{F} \& \mathrm{~V}$ stamp is lower than the lowest value (among consumers) of the initial $F \& V$ expenditure. In other words, the $F \& V$ stamp acts only through a change in income (the second channel identified in the model section) and not through a direct increase in consumption (the first channel identified in the model section). 


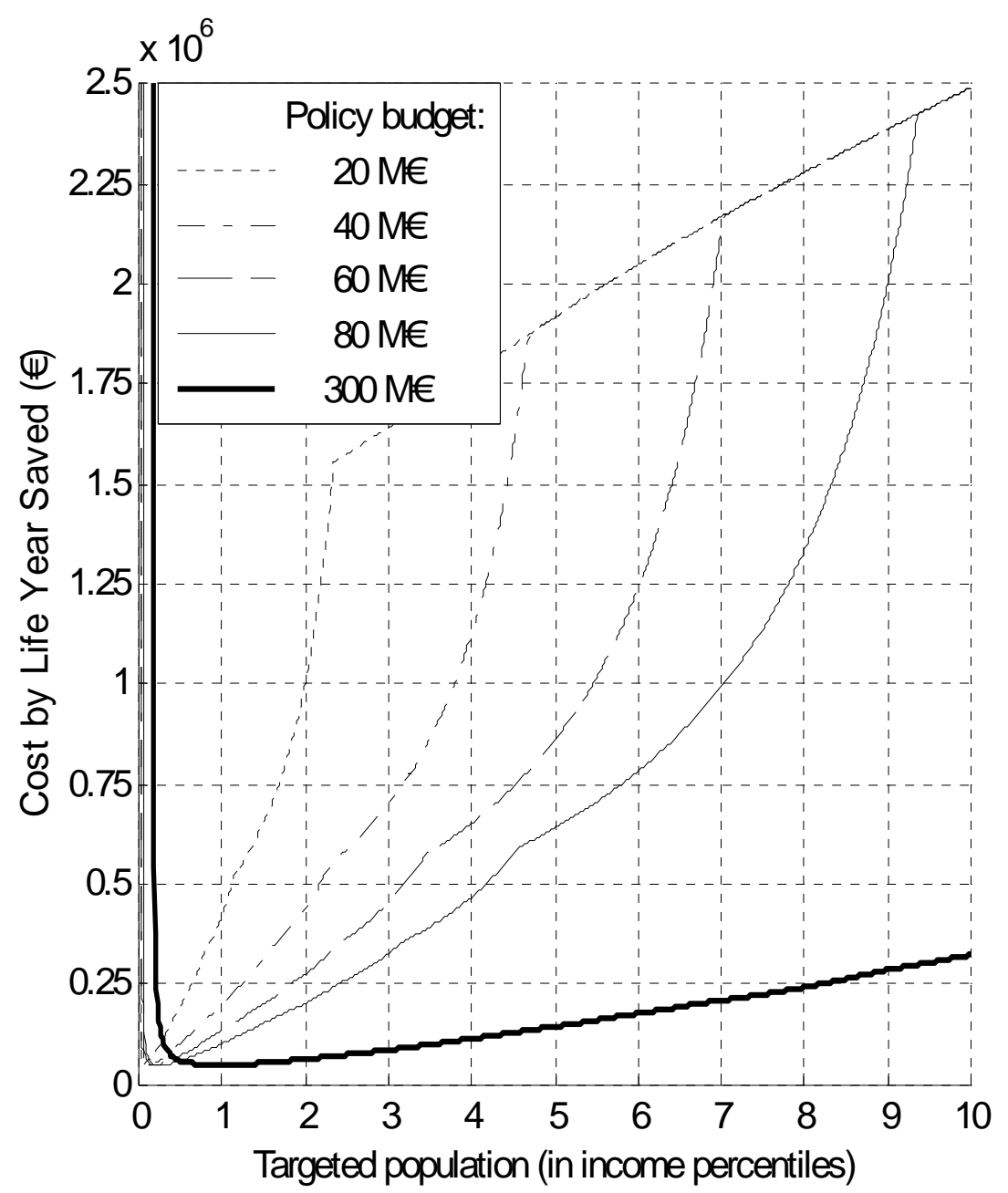

Figure $2 b$. Cost by LYS according to the size of targeted population (Total budget $=20,40,60,80,300 \mathrm{M} €$ )

\section{Optimal targeting}

Figure 3a provides iso-LYS curves when both the targeting and the total amount of funding vary. For a given funding, the number of LYS increases when the size of the targeted population decreases (e.g., for $250 \mathrm{M} €, 1000$ LYS are obtained when targeting the poorest 7\%, 3000 LYS for 2.5\%, and 5000 LYS for 1\%). Besides, higher resources devoted to the policy allow increasing the rate of targeting or the number of LYS (e.g. going from $225 \mathrm{M€}$ targeted on the $2 \%$ poorest to $300 \mathrm{M} €$ can be done at iso-LYS 3000 by targeting the $3.5 \%$ poorest, or at iso-target 2\% resulting in 5000 LYS). Finally, iso-LYS curves are increasing 
with the size of the targeted population. This means that the most cost effective policy for a given number of LYS is reached at the left end of each curve (e.g. around 240M€ for the $0.8 \%$ poorest to obtain 5000 LYS). The most cost-effective budget-target policies are also represented on Figure 3a (see dotted lines).

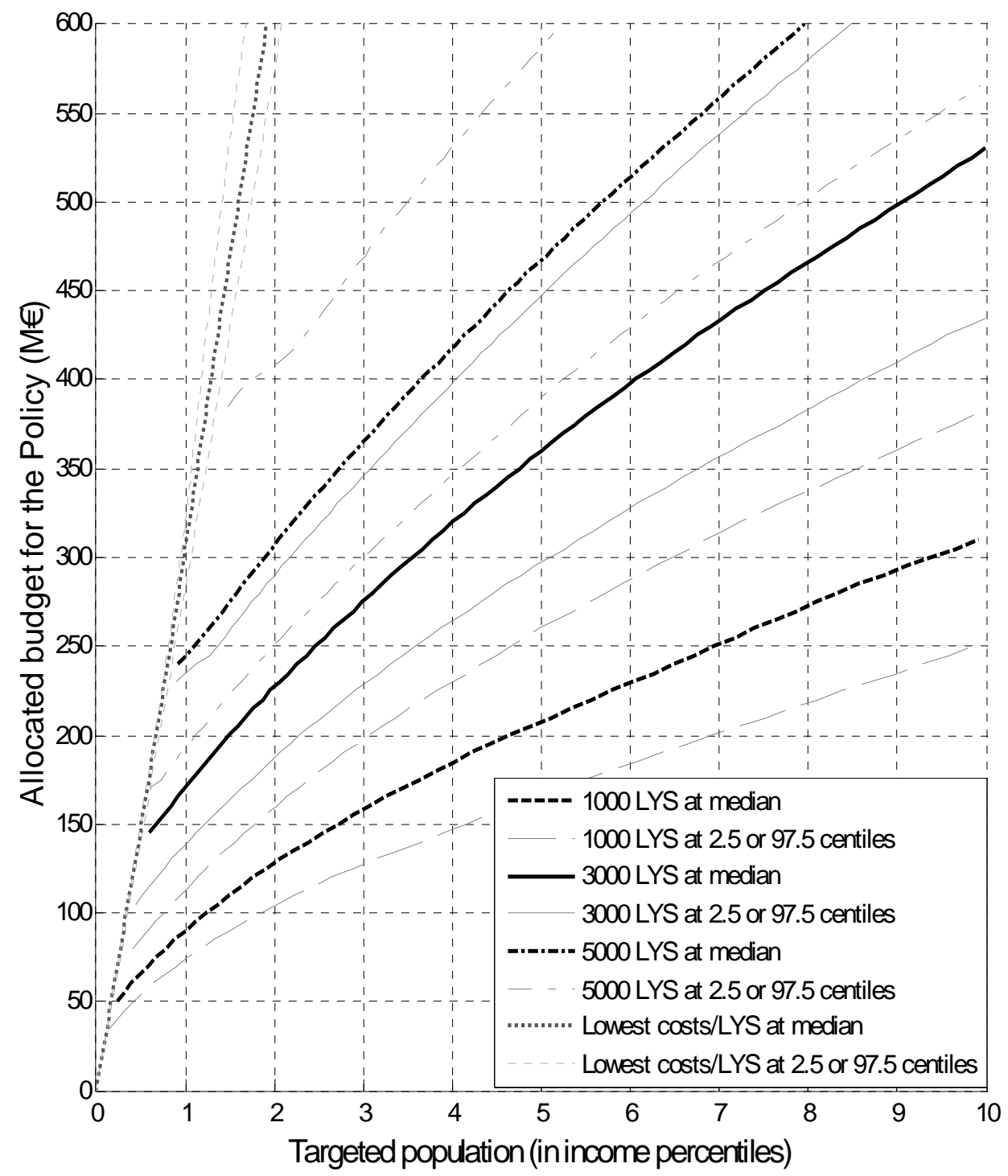

Figure 3a. Iso-LYS (Life Years Saved) curves and lowest costs by LYS curves, according to the size of the targeted population and the total budget allocated to the F\&V stamps

Similarly, Figure 3b presents iso-cost by LYS curves. It shows that, for instance, the costeffectiveness level of $80 \mathrm{k} € / \mathrm{LYS}$ can be reached by targeting $1 \%$ of the population with 
$100 \mathrm{M} €$ and 4\% of the population with $450 \mathrm{M} €$. Contrarily to Figure 3a, in Figure 3b, all left ends are at $(0,0)$ : nobody targeted (and thus no budget allocated). Hence, all costs by LYS are possible either for a given target or for a given budget, as long as they are chosen above a minimum threshold (around $50 \mathrm{k} €$ for the median, $40 \mathrm{k} €$ for the 2.5 centile and $75 \mathrm{k} €$ for the 97.5 centile, as shown on Figure 2a).

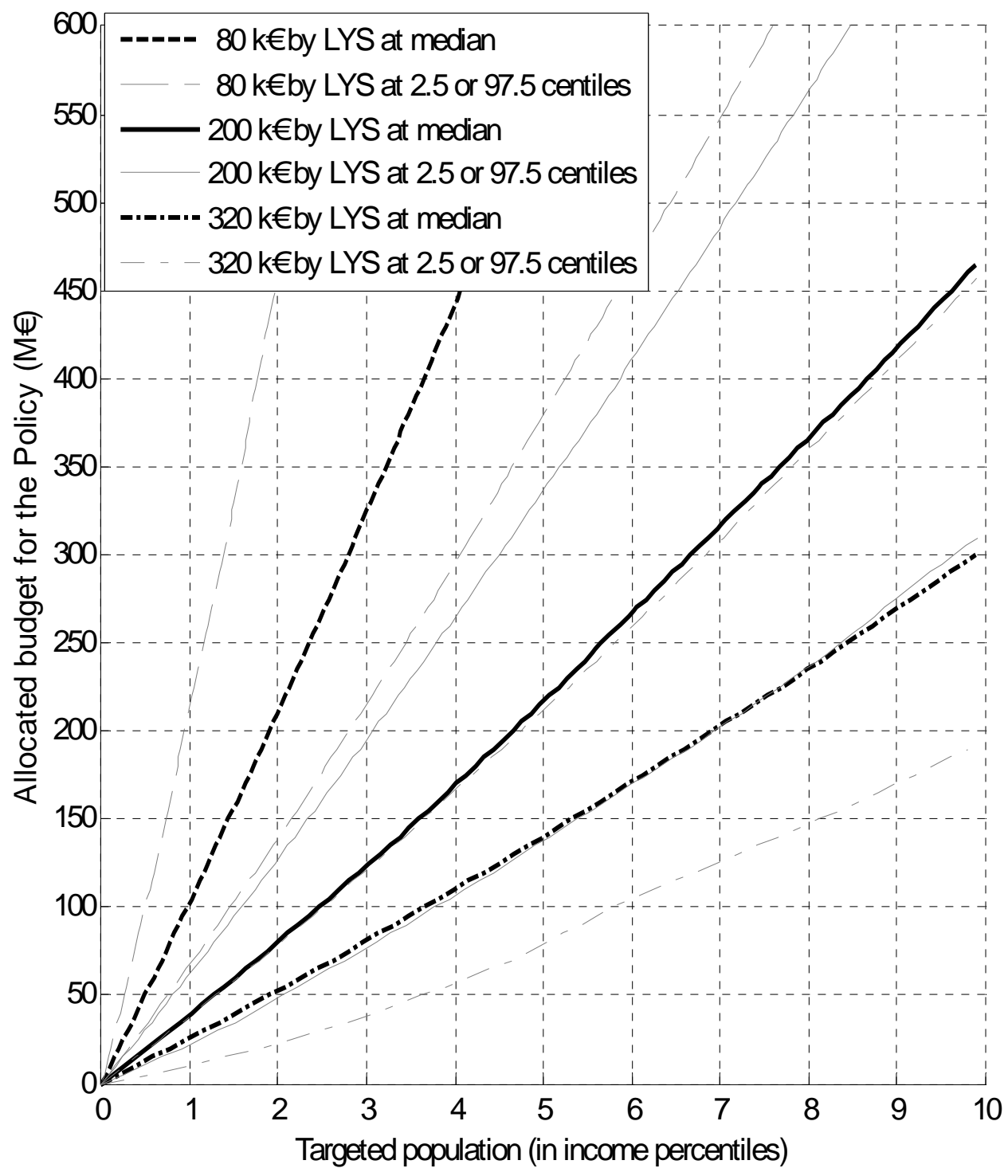

Figure 3b. Iso-cost by LYS (Life Year Saved) curves according to the size of the targeted population and the total budget allocated to the F\&V stamps 


\section{Discussion}

The analysis presented in this paper, based on collaboration between economists and epidemiologists combined two models: an economic model which predicts how $\mathrm{F} \& \mathrm{~V}$ consumption is affected by a change in policy and a health model which evaluates the impact of a change in F\&V consumption in terms of DA and LYS. Finally we computed the costs per DA and LYS as the ratios between the taxpayer cost of the policy and the numbers of DA and LYS.

The interest of this approach is to propose ex ante analysis of the cost-effectiveness of policies whereas the large majority of works analyzing cost-effectiveness of health policies are based on ex post evaluation of policies or on ex post evaluation of experiments. Such an approach has been used previously for analyzing the possible effects of consumption subsidies for healthier foods (Cash et al., 2005) and for assessing the impacts of alcohol pricing policies and modelling the effect of consumption changes on mortality and disease prevalence (Purshouse et al., 2010).

The main findings of the present study are: (1) at the aggregate level, a F\&V stamp policy has a modest impact on consumption and as a result on health gains; (2) when well designed, the F\&V stamp policy may significantly increase the $F \& V$ consumption of low-income households; (3) for a given budget allocated to the policy, the benefit of the policy increases and the cost per DA or LYS decreases when the number of beneficiaries decreases; (4) to maximize the cost-effectiveness of the $\mathrm{F} \& \mathrm{~V}$ stamp policy, the targeted population must be rather small; (5) when well designed, the F\&V stamp policy (targeted policy) is more cost- 
effective than a VAT decrease ${ }^{10}$ (non targeted policy); (6) a stamp policy might generate an increase in the price of $\mathrm{F} \& \mathrm{~V}$ thus reducing the consumption and the health benefits within the non targeted population.

Despite the large shifts in $\mathrm{F} \& \mathrm{~V}$ intake in the targeted population, the total life gains appear to be quite modest. Indeed the expected benefits of $\mathrm{F} \& \mathrm{~V}$ consumption, estimated from most recent meta-analyses, are moderate compared to earlier estimations based on case-control studies. Moreover although the burden of cancer and cardiovascular diseases represents more than 2/3 of total deaths in France, the favorable association with F\&V consumption is documented for only about half of their etiologies (1/3 of total deaths). This means that the overall impact of increasing $\mathrm{F} \& \mathrm{~V}$ intake on total mortality is calculated on this third of total deaths.

As mentioned in the paper, the F\&V stamp acts through two channels. The most effective channel requires providing to the targeted consumers a stamp whose value is larger than their initial $\mathrm{F} \& \mathrm{~V}$ expenditure. For a given total amount allocated to the F\&V stamp program, this happens only when a 'small' number of consumers are selected. The other channel is less effective as the F\&V stamp is equivalent to an increase in income and can therefore be used for any purpose. Thus the cost effectiveness of the policy increases when targeting a smaller share of the LIC population.

In a recent paper Alston et al. (2008) put forward the fact that the induced changes in prices related to food stamps limited to healthy food consumption could result in decreases in consumption of healthy foods by non-targeted households. In our analysis, we identify such a non intentional effect: the policy increases the consumption of a small share of the population

\footnotetext{
${ }^{10}$ For a $300 \mathrm{M} €$ budget, the F\&V stamp policy is more cost-effective than the VAT reduction policy if the targeted population is smaller than around $3 \%$ of the population (and the individual value of the stamp greater than $230 € /$ person/year).
} 
while it slightly decreases the consumption of $\mathrm{F} \& \mathrm{~V}$ of a large share of the population. According to our simulations, this non intentional effect reduces by 20 to $25 \%$ (depending on the targeting rate) the number of DA induced by the policy. It is important to understand that this non intentional effect is due to the increase in the price of $F \& V$. This increase in price depends on the additional demand generated by the policy but also on the supply response. In the short term, elasticities of supply are rather small, thus amplifying this issue. In the long run, elasticities of supply tend to be high thus limiting the price increase. For instance, simulations made with supply elasticity equal to 3, show that the deleterious impact of the policy on non targeted population is smaller: in this case, when targeting $2 \%$ of the population, the non intentional effect only reduces by around $10 \%$ the number of DA induced by the policy.

Clearly, our results must be considered in relation with some limitations that open up the scope for further research. On the health model side, we limited our analysis to the assessment of DA and LYS. It is likely that considering only these criteria led us to underestimate the health benefits related to $\mathrm{F} \& \mathrm{~V}$ consumption. It would be useful to widen the analysis by taking into account the possible effects of the policies on the health care costs and the morbidity levels. By doing so, it would possible to evaluate the variations of Quality Adjusted of Life Year Saved (QALYS) induced by the studied policies.

On the economic model side, we focused on a product category rather than considering a system of demand for food. Thus we ignored the substitutions that might occur with other foods which might have health impacts. On the other way, considering the F\&V sector as a single product category prevented us from taking into account the heterogeneity of price sensitivity according to the type of products within this sector. Elsewhere we considered that 
whatever their income consumers buy the same good at the same mean price and we ignored the possibility of quality differences. It is not necessarily the case and it is likely that the mean price of purchased F\&V depends on the consumers' category. Moreover we assumed that an income increase led to an increase in the quantity of F\&V bought by the households rather than to an increase in their quality (possibly with no increase in the quantity). Technically it is possible to deal with these issues. However, it would be necessary to get more information about the heterogeneity of price sensitivity of consumers according to the type of products within the $F \& V$ category and the quality choice by consumers when their incomes change.

Another limit is related to the modeling of stamps. We have assumed that consumers do not resell the stamps and do 'eat' the additional quantities of F\&V they buy, that they consider stamps as an increase in income (as long as the value of the stamp is not too high) and that the stamps do not convey any information. These are three strong assumptions.

Indeed, due to the first assumption, we over-estimate the impact of stamps. Thus reselling stamps (or selling the products one buys with the stamps) is equivalent to an increase of the size of the targeted population. We have seen that a larger targeting leads to a lower costeffectiveness. The reasons for which consumers might want to sell the stamps or the products are numerous. Among others, it is well known that modifying his/her diet is difficult and that it is not only budget constraints that fully explains a low consumption in F\&V. Contrary to the second assumption, it is possible that some consumers consider that they have to buy some F\&V with the stamps in addition to what they already buy. Social norms for instance could explain such practices and lead to larger effects than those assessed in our analysis. Finally, the third assumption led us to under-estimate the impact of food stamps by ignoring the fact that the stamp can convey some information and contribute to nutritional education that might change the consumers' demand. 
Despite these limitations, the approach proposed in this paper contributes to open an interesting field of research and gives some results that are important to consider before implementing a public health policy related to food consumption. Indeed, we show that, in this case, the trade-off between targeted versus population-based policies is influenced by factors which determine the market equilibriums (price, income and supply, size of the targeted population...). Contrary to previous research in public health, we show that population-based strategies are not necessarily more cost-effective than targeted strategies when the impacts of the policies depend on such economic variables. 


\section{References}

Ahern J., Jones M. R., Bakshis E, Galea S., 2008. Revisiting Rose: Comparing the Benefits and Costs of Population-Wide and Targeted Interventions, The Milbank Quarterly, 86(4): 581-600.

Allais O., Bertail P., Nichèle V. 2010 . The Effects of a Fat Tax on French Households‘ Purchases, American Journal of Agricultural Economics, 92(1) : 228-245.

Alston J.A., Conner C., Mullally a, Sumner D., Likely effects on obesity from proposed changes to the US food stamp program, Food Policy 34 (2009) 176-184.

Andrieu, E., and Caillavet, F. (2006). Inégalités nutritionnelles au sein des ménages : la pauvreté jouet-elle un rôle ? Cahiers de Nutrition et de Diététique 41(2), 75-85.

Andrieu, E., Caillavet, F., Lhuissier, A., Momic, M., and Regnier-Chauvel, F. (2006). L'alimentation comme dimension spécifique de la pauvreté. Approches croisées de la consommation alimentaire des populations défavorisées. In "Les travaux de l'Observatoire national de la pauvreté et de l'exclusion sociale 2005-2006" (s. Observatoire national de la pauvreté et de l'exclusion, Ed.), pp. 247-278.

Bihan H., 2008. Providing an economic supplement for fresh F\&V purchase, Fruit and Vegetable Summit Proceedings, EGEA - IFAVA / WHO, Paris.

Bihan H., Casteltbon K., Mejean C., Peneau S., Pelabon S., Jellouli F., Le Clesiau H., S. Hercberg, 2010. Sociodemographic Factors and Attitudes toward Food Affordability and Health Are Associated with Fruit and Vegetable Consumption in a Low-Income French Population, Journal of Nutrition, 140(4): 823-830.

Blisard, N., Stewart, H., Jolliffe, D., 2004. Low-income households’ expenditures on fruits and vegetables. Agricultural Economic Report No. 833, US Department of Agriculture, Economic Research Service.

Bouamra-Mechemache Z. and V. Réquillart. 2000. Analysis of EU Dairy Policy Reform. European Review of Agricultural Economics 27(4): 409-430

Cassady D, Jetter KM, Culp J, 2007. Is Price a Barrier to Eating More Fruits andVegetables for LowIncome Families? Journal of the American Dietetic Association, November 2007, 1909-1915. 
Cash SB, Sunding DL, Zilberman D. Fat Taxes and Thin Subsidies: Prices, diet, and health outcomes. Food Economics. 2005; 2(3-4); 167-174.

Chen, Z., Yen, S., Eastwood, D., 2005. Effects of food stamp participation on body weight and obesity. American Journal of Agricultural Economics 87 (5), 1167- 1173.

Dallongeville J., L. Dauchet, O. de Mouzon, V. Réquillart and L.G. Soler. Increasing fruit and Vegetable Consumption : A cost-Benefit Analysis of Public Policies. European Journal of Public Health, (2010), doi:10.1093/eurpub/ckq013

Dauchet L, Amouyel P, Dallongeville J. Fruit and vegetable consumption and risk of stroke: a metaanalysis of cohort studies. Neurology. 2005 ; 65(8):1193-1197.

Dauchet L, Amouyel P, Hercberg S, Dallongeville J. Fruit and Vegetable Consumption and Risk of Coronary Heart Desease: A Meta-Analysis of Cohort Studies. Journal of Nutrition. 2006; 136; 25882593.

Dibsdall A., Lambert N., Bobbin R.F., Frewer L.J., 2007. Low-income consumers’ attitudes and behaviour towards access, availability and motivation to eat fruit and vegetables, Public Health Nutrition: 6(2), 159-168

Drewnowski A, Darmon N, Briend A. Replacing fats and sweets with vegetables and fruits-A question of cost. American Journal of Public Health. 2004;94:1555-1559.

Drewnowski A, Specter SE, 2004. Poverty and obesity: the role of energy density and energy costs. American Journal of Clinical Nutrition, 79, 6-16.

Drewnowski A, Darmon N, 2005. Food choices and diet costs: an economic analysis. Journal of Nutrition 135, 900-904.

French SA, Story M, Jeffery RW. Environmental influences on eating and physical activity. Annual Review of Public Health. 2001;22:309-335.

Fox, M.K., Cole, N., 2004. Nutrition and health characteristics of low-income populations. Food Stamp Program Participants and Non-Participants, vol. I. US Department of Agriculture, Economic Research Service, December 2004. 
Fox, M.K., Hamilton, W., Lin, B., 2004. Effects of food assistance and nutrition programs on nutrition and health. Executive summary of the literature review, vol. 4. Food Assistance and Nutrition Research Report No. 19-4, US Department of Agriculture.

Frazao, E., Andrews, M., Smallwood, D., Prell, M., 2007. Food spending patterns of low-income households: will increasing purchasing power result in healthier food choices? Economic Information Bulletin, Number 29-4, September 2007.

Frongillo EA, 2003. Understanding obesity and program participation in the context of poverty and food insecurity. Journal of Nutrition 133, 2117-2118.

Gibson, D., 2003. Food stamp program participation is positively related to obesity in low income women. Journal of Nutrition 133 (7), 2225-2231.

Gibson, D., 2006. Long-term food stamp program participation is positively related to simultaneous overweight in young daughters and obesity in mothers. Journal of Nutrition 136 (4), 1081-1085. Guthrie, J.F., Lin, B.H., Ver Ploeg, M., Frazao, E., 2007. Can food stamps do more to improve food choices? Economic Information Bulletin Number 29-1, US Department of Agriculture, Economic Research Service, September 2007.

Herman D.R., Harrison G., Afifi A., Jenks E., 2008. Effect of a Targeted Subsidy on Intake of Fruits and Vegetables Among Low-Income Women in the Special Supplemental Nutrition Program for Women, Infants, and Children, American Journal of Public Health. 2008;98:98-105.

Jetter K.M., Chalfant J.A., Sumner D.A., 2004. An Analysis of the Costs and Benefits to Consumers and Growers from the Consumption of Recommended Amounts and Types of Fruits and Vegetables for Cancer Prevention, Final report prepared for the California Department of Health Services Cancer Prevention and Nutrition Section, University of California, Agricultural Issues Center, April 2004. Jones S.J., Frongillo E.A., 2006. The Modifying Effects of Food Stamp Program Participation on the Relation between Food Insecurity and Weight Change in Women, J. Nutr. 136:1091-1094. Landers P.S., 2007. The Food Stamp Program: History, Nutrition Education, and Impact, J Am Diet Assoc., 107:1945-1951.

Le Blanc, M., Lin, B.H., Smallwood, D., 2007. Food assistance. How strong is the safety net? Amber Waves 5, 40-45 (special feature). 
Lin, B., Guthrie, J., 2007. How do low-income households respond to food prices? Economic Information Bulletin 29-5, September 2007.

Lock K, Pomerlau J, Causer L, Altmann DR, McKee M. The global burden of disease attributable to low consumption of fruit and vegetables: implications for the global strategy on diet. Bull World Health Organ. 2005;83:100-108.

Lusk J. and J.D. Anderson, 2004. Effects of country-of-origin labeling on meat producers and consumers. Journal of Agriculture and Resource Economics, 29(2): 185-205.

Meyerhoefer, Chad D., Pylypchuk, Y., 2008. Does participation in the food stamp program increase the prevalence of obesity and health care spending? American Journal of Agricultural Economics 90 (2), 287-305.

Murray CJ. Quantifying the burden of disease: the technical basis for disability-adjusted life years. Bull World Health Organ. 1994;72(3):429-45.

Nichèle V., 2003. Health Information and Food demand in France, in Health, Nutrition and Food demand, Ed. W.S Chen and Rickertsen, CABI Publishing, pp 131-151.

Olson C.M., 1999. Nutrition and Health Outcomes Associated with Food Insecurity and Hunger, $J$. Nutr. 129: 521S-524S.

Pan, S., Jensen, H., 2008. Does the food stamp program affect food security status and the composition of food expenditures? Journal of Agricultural and Resource Economics, 40 (1), 21-35. Purshouse R.C., Meier P.S., Brennan A., Taylor K.B., Rafi R., 2010. Estimated effect of alcohol pricing policies on health and health economic outcomes in England: an epidemiological model, Lancet, 375: 1355-64.

Rose G., 1992. The Strategy of Preventive Medicine. Oxford: Oxford University Press.

Rose, G., 2001. Sick Individuals and Sick Populations. International Journal of Epidemiology, 30:427-32.

Saurel-Cubizolles MJ, Chastang JF, Menvielle G, Leclerc A, Luce D. 2009. Social inequalities in mortality by cause among men and women in France. Journal of Epidemiology and Community Health, 63: 197-202. 
Shenkin JD, Jacobson MF., 2010. Using the Food Stamp Program and Other Methods to Promote Healthy Diets for Low-Income Consumers. American Journal of Public Health, 100(9), 1562-1564. Ver Ploeg, M., Mancino, L., Lin, B., 2007. Food and nutrition assistance programs and obesity: 19762002. Economic Research Report No. 48, US Department of Agriculture, Economic Research Service, September 2007.

Webb A.L., Schiff A., Currivan D, Villamor E, 2008. Food Stamp Program participation but not food insecurity is associated with higher adult BMI in Massachusetts residents living in low-income neighborhoods, Public Health Nutrition: 11(12), 1248-1255

Wilde P, McNamara P, Ranney C. 1999. The effect of income and food programs on dietary quality: A seemingly unrelated regression analysis with error components. American Journal of Agricultural Economics, 81:959-971.

Wilde PE, McNamara PE \& Ranney CK, 2000. The Effect on Dietary Quality of Participation in the Food Stamp and WIC Programs. http://www.ers.usda.gov/publications/fanrr9.pdf/ (accessed July 2010).

Wilde, P., Nord, M., 2005. The effect of food stamps on food security: a panel data approach. Review of Agricultural Economics 27 (3), 425-432

Wohlgenant M.K., 1993. Distribution of gains from research and promotion in multi-stage production systems: the case of the US beef and Pork industries. American Journal of Agricultural Economics, 75(3): 642-651.

Zulman D.M., Sandeep V., Omenn G.S., Hayward R.A., 2008. The Relative Merits of PopulationBased and Targeted Prevention Strategies, Milbank Quarterly, 86(4): 557-580. 